5. If with each of the functions $f(x)$ considered above we draw pencils of straight lines through the origin corresponding to integral values of the slopes of the lines, we obtain the nomograms from which rapid but not very accurate solutions may be derived for any member of the family $f(x) \pm k x=c$. H. Peat.

\title{
DUNCAN MCLAREN YOUNG SOMMERVILLE
}

IT is with deep regret that I record the death of Professor D. M. Y. Sommerville on the 31st January, 1934. Professor Sommerville was a fairly frequent contributor to the Gazette, and his work, especially in geometry, was well known. He had been suffering from heart trouble and had been forced to take a rest in September last. However he seemed to make a fairly good recovery and was arranging the work of the 1934 session with me on Tuesday, January 30 th. The next day he died at the early age of 54 . He leaves a widow for whom much sympathy is felt. He had the satisfaction of finishing his Analytical Geometry of Three Dimensions which has just been published by the Cambridge University Press.

As his assistant for eight years I had an opportunity of appreciating his admirable qualities as a teacher, a mathematician, and a man. His early death is an irreparable loss.

F F. MrLes.

\section{CORRESPONDENCE.}

To the Editor of the Mathematical Gazette.

In the May number of the Gazette I read with much interest the account of the discussion on "Differentjals" which took place at this year's Annual Meeting of the Mathematical Association. As my article on the "Teaching of Differentials" started all the trouble, perhaps I may be allowed to intervene again. I much regret that I was unable to be present at the meeting to join in the discussion, but I am glad to see that although opinions differ I have some supporters in the advocacy of the early teaching of differentials. Personally I welcome the appearance of those elementary text-books whose authors have been bold enough to introduce differentials to schoolboys. It is particularly encouraging to me, as I feel that my advocacy of the early teaching of differentials might be open to the criticism that I am not well enough acquainted with the difficulties of the schoolmaster; but when I see schoolmasters themselves not afraid to mention a "differential" (of the kind in which I am myself interested) I feel that I cannot fairly be charged with a biased opinion on the matter.

In fairness to my namesake I should like to clear up any doubt that there may be as to my identity. One of the speakers made a facetious reference to "two mathematicians having the same name and initials." The blame for that cannot be laid to the charge of either of us, though a friend once told me it was going to cause me a lot of trouble! The two E. G. P.'s have by mutual agreement decided that the Bangorian, who is the writer of this note, shall be, known as "E. G. Phillips" and the Oxonian now calls his " mathematical self" Eric Phillips.

E. G. P.

University College, Bangor. 